\title{
Enhanced biotic recovery through KPB transition: Evidence from the Mahadeo-Cherrapunji Section, Meghalaya, India
}

\author{
SUCHARITA PAL ${ }^{1}$, M. S. KALPANA ${ }^{2}$, J. P. \\ SHRIVASTAVA ${ }^{3 *}$
}

${ }^{1}$ Center for Earh, Ocean and Atmospheric

Science, University of Hyderabad, Hyderabad 500046 (sucharita9@gmail.com)

${ }^{2}$ National Geophysical Research Institute

(Council of Scientific and Industrial

research), Uppal Road, Hyderabad 500 606,

India (kalpana.rms@gmail.com)

${ }^{3}$ Department of Geology, University of Delhi, Delhi-110007, (*correspondance:

jpshrivastava.du@gmail.com)

Previous studies on Mahadeo-Cherrapunji section (MCR) revealed Cretaceous/Palaeogene boundary (KPB) in the shelf sediments. But, major biotic changes at KPB (ca. 66 Ma) remain inconclusive. Moreover, Deccan volcanism induced environmental stress led to mass extinction, played major role in the southern hemisphere. In this context, Organic Matter (OM) trapped within the Maastrichitian and Danian shelf sediments attains significance and necessitated detailed study. Present findings were compared to continuous, shallowmarine Um-Sohryngkew river (USR) KPB section, marked with abundant short chain $n$-alkanes (SCA) and $n$-fatty acids. These biomarkers originated from autochthonous marine algal remains, correlate well with the GSSP. High-resolution $n$-alkane and $n$-fatty acid records across KPB of the MCR section is presented in this paper. Notable $\sim 6$-fold rise in the SCA is marked within the thin KPB clayey layer that lies between $\mathrm{CF} 1$ and $\mathrm{P} 0$ biozones. The even carbon numbered SCA ( $n$-C16 or $n$-C18) predominance is attributed to thermal degradation and partial combustion of non-woody biomass. Although, the dominance of $\mathrm{C} 17 \mathrm{n}$-alkane and hopanes is suggestive of algae, fungi and bacteria as a biotic source of the organic matter (SOM). A sudden rise in the SCA between $\mathrm{CF} 1$ and $\mathrm{P} 0$ biozones is coinciding with the major foramniferal break. But, in USR section, similar anomaly was recorded within the lower CF3 biozone preceded by a major foramniferal break. Extra-basinal tectono-thermal effects, frequent local sea-level changes and greenhouse effects of volcanism were accountable for sudden rise in the temperature causative for biotic stress, leading to biotic turnover in shelf waters. 